Article

\title{
Experimental Effects of Priming on Affective Responses to Acute Exercise
}

\author{
Ovuokerie Addoh ${ }^{1,2}$, Robert Sanders ${ }^{1}$ and Paul Loprinzi ${ }^{1, *}$ (i) \\ 1 Department of Health, Exercise Science and Recreation Management, The University of Mississippi, Oxford, \\ MS 38677, USA; addoh001@umn.edu (O.A.); rtsander@go.olemiss.edu (R.S.) \\ 2 Department of Rehabilitation Medicine, University of Minnesota, Minneapolis, MN 55455, USA \\ * Correspondence: pdloprin@olemiss.edu
}

Received: 11 June 2019; Accepted: 21 January 2020; Published: 8 February 2020

check for updates

\begin{abstract}
The purpose of this study was to experimentally investigate the relationship between positive affect elicitation (using a short video clip) prior to exercise and affect during acute aerobic exercise. A counterbalanced, within-subject experimental design was used. We conducted three related experiments. In Experiment 1, 30 adults aged 18-40 years participated in a positive affect-elicitation condition ("affective priming") and a control condition. Participation involved watching a five-minute video clip, as well as walking on a treadmill at a (self-selected) brisk pace for ten minutes. We compared affective ratings at baseline and intra-exercise for both conditions using a 2 (condition; priming versus no priming) $\times 2$ (time; pre- versus mid-exercise) repeated measures ANOVA. In the follow-up experiments, we re-examined the relationship between affective priming and intra-exercise affect, addressing some limitations noted with Experiment 1. In Experiment 2, we compared the affect-elicitation properties of self-selected and imposed video clips. In Experiment 3, we re-investigated the potential affective benefits of priming, while including a neutral (neither positive nor negative) video during the control condition to attenuate potential demand characteristics, and a positive video-only condition to investigate possible carryover effects. Self-selected and imposed film clips showed similar affect-elicitation properties. Comparing the priming and control conditions, there were notable differences in the mean intra-exercise affective valence ratings ( $p=0.07$ Experiment 1, $p=0.01$ Experiment 3). The mean affective activation ratings were not significantly different ( $p=0.07$ Experiment $1, p=0.86$ Experiment 3 ). Priming the affective state prior to exercise may be beneficial for enhancing intra-exercise affect.
\end{abstract}

Keywords: Affective priming; exercise; video; hedonic theory; enjoyment; mood

\section{Introduction}

Physical activity behavior is influenced by psychological factors, such as self-regulation, self-efficacy, attitude, vicarious experiences, intention, beliefs, and perceived pros and cons, as well as demographic, sociocultural, and environmental factors [1]. Some of the aforementioned factors comprise key constructs of behavior theory, and have been utilized with some success in behavior change programs [2,3], although each of these theoretical approaches in themselves does not completely account for adequate levels of explained variance in physical activity behavior [4]. Hence, there is a need to further explore antecedents of physical activity behavior. Notably, how an individual feels during exercise appears to be an important correlate of physical activity behavior [5]. Consciously-accessible feelings_-"core affect" [6] - are often described along two dimensions: valence (good versus bad) and activation (high versus low) [7]. Per psychological hedonism, individuals tend to innately seek positive affective states and avoid negative situations [6]. In alignment with this, in a 
recent meta-analysis, Kates and Rhodes demonstrated that affect during exercise (as opposed to after exercise) was a predictor of future physical activity behavior [5].

Physical activity at low to moderate intensities has been shown to have a positive influence on affect and mood states [8-11]. Mechanisms potentially underlying this effect, such as neural pathways, biological changes in neurochemicals, and the psychological distraction hypothesis, have been described elsewhere [12-16]. Per the model of Affective Response Generation (ARG), affective responses to exteroceptive and interoceptive exercise-related stimuli are generated through subcortical and cortical pathways, with the amygdala as an important relay station [15,17]. Neurochemical changes in monoamines (such as dopamine and serotonin), endogenous opioids, endocannabinoids, and endorphins are also plausible affective-eliciting mechanisms of acute exercise [12-14]. While this "feel-good" effect is not completely understood, it may seem counterintuitive in view of the current inactivity pandemic across the United States and around the world [18-20]. Furthermore, what is less clear is how to optimize this positive affective experience with exercise. Hence, methods to accentuate the feel-good response associated with exercise need to be further explored.

The decision to be physically active may be driven by dual processes [21,22]. On the one hand, cognitive awareness of the benefits of exercise on physical and mental wellbeing is an important predictor for exercise behavior. Theories of health-related behavior, such as the Health Belief Model [23] explore this decision-making process. On the other hand, subconscious processes, such as feelings associated (not core affect or feelings experienced during exercise) with exercise may play an important role in determining habitual behavior [5]. Per the affective primary hypothesis, automatic affective evaluation occurs prior to cognitive analysis [24,25]. Hence, when evaluating the desire for physical activity (PA), people are more likely to initially think of how it makes them feel, prior to an appraisal of the associated benefits. The affective reflective theory (ART) attempts to describe the interconnection between cognitive and affective processes with exercise behavior [6]. Summarily, "the ART of physical inactivity and exercise is a dual-process theory that emphasizes the role of momentary and anticipated affect, but without losing sight of the fact that cognitive insight and more complex reflection are important and necessary to long-term changes in exercise behavior as well" [6]. In our earlier work, we also described a conceptual inter-relationship between cognitive analysis, affect, and future exercise [26].

Recognizing the relationship between affective evaluations and habitual physical activity, the American College of Sports Medicine (ACSM) 2013 guidelines (page 374) recognized that "feelings of fatigue and negative affect can act as a deterrent to continued participation" [27]. Furthermore, also recognizing the role of exercise-related affect as an important antecedent for future behavior, organizations such as the North American Society for the Psychology of Sport and Physical Activity (NASPSPA) and the Exercise and Sport Psychology Division of the American Psychological Association (APA) promote research on this topic [28].

While exploring the subject, Ruby et al. noted that people tend to underestimate how much they would enjoy exercising (affective forecasting bias), due to disproportionate weight being placed on the initiation of the exercise session [29]. It may therefore be intuitive that enhancing the affective experience prior to exercise may accentuate the affective evaluation during exercise. One method to achieve this could be by reorganizing the exercise routine in such a manner that the more pleasant routines are performed early on [29]. This technique may, however, be limited when the order of the exercise routine is functional. An unexplored potential strategy is the use of "affective priming".

Priming attempts to act on the subconscious decision-making process. It involves the use of valence-congruent stimuli to increase sensitivity to successive (target) experiences [30,31]. For example, the evaluative processing of the target word "love" may proceed faster and more accurately when preceded by the word "sunshine" as compared to "death" [31]. In the context of exercise, the processing of the target positive affective response may be enhanced when preceded by a humorous video experience. Therefore, this postulates the idea that there may be an additive effect generated from stimulation via priming prior to exercise and then in conjunction with exercise. Although traditional views on optimizing task performance emphasize concentration on the task, studies have found that 
by inducing humor individuals experience more stable positive affect [32]. Priming has been applied with investigating the development of first impressions following visual primes [24], the stimulation of intrinsic motivation [33], as well as goal-directed [34,35] and competitive behavior [36].

Priming occurs through spreading activation across linked concept nodes, as well as through response competition $[30,31]$. With spreading activation, the antecedent valence-congruent stimulus lowers the threshold for transmission of the subsequent impulse. Response competition means that the successive response following a prime is more automatic if the target experience is of congruent valence. Hence, viewing a humorous video a-priori may lower the threshold for experiencing pleasure with exercise, as well as increase the automaticity of this reaction through response competition. Priming techniques may be applied to subconsciously modify the psychological state of an individual before and during a task [33]. Additionally, the use of video priming techniques to influence motivational state and anaerobic performance has also been explored with some success [35].

The use of videos to induce an affective experience has been the subject of several research articles. Conversely, only a few studies have explored the use of videos for affective-elicitation purposes within the exercise domain [35]. Although other methods for acutely altering mood have been explored, such as music, pictures, and personal recollection [37], videos are thought to be advantageous, as they are engaging for extended periods (attentional capture) and in a manner consistent with real life experiences [37,38]. Videos may improve mood (prime affect apart from exercise) by offering temporary distraction from negative stimuli. Furthermore, the mirror rule [39], an instinctive process of mimicking visual expressions seen, and the brain's subsequent interpretation of this copied expression from a video stimulus, are thought to play a role in the influence of videos on affect. The perception of the (mirrored) events in a video may be influenced by a combination of sensory cues, previous knowledge, and generated inferences following situational appraisal of the ongoing experience, broken down into episodes-event segmentation theory $[39,40]$. This may be contributory to inter-individual differences in perception of affect-eliciting videos. The lateral prefrontal cortex, a key brain structure subserving executive control and decision-making, is thought to be involved in the representation of these events [40], with perceptual prediction error assessed by the anterior cingulate cortex and subcortical neuromodulatory systems [40]. Affective responses to videos may also be influenced by changes in monoamines [41].

Since comparable psychological, neural (subcortical and cortical), and neurochemical pathways are implicated in the generation of exercise and video-related perception of affect $[15,39,40]$, it is plausible that when these activities are paired sequentially, there may be a heightened affective response. Therefore, the purpose of our research is to experimentally investigate whether positive affect elicitation using a short video clip prior to exercise would enhance the intra-exercise (during exercise) affective evaluation. Previous research has shown some utility of videos in promoting motivation for exercise [35], as well as in the elicitation of affective states [38,42]. However, the utility of a positive-affect video clip in accentuating the positive affective response to exercise is yet to be extensively examined.

We conduct three related studies, aimed at exploring the relationship between positive affect elicitation (using a short video clip) prior to exercise and affect during acute aerobic exercise. Experiment 1 is a pilot study exploring this potential association. In Experiment 2, we examine the affect-eliciting properties of selected video clips in a sample from a predominantly college student population. In Experiment 3, we attempt to replicate the pilot study (Experiment 1), with some revisions.

\section{Experiment I}

\subsection{Purpose}

The purpose of this pilot study was to experimentally investigate whether positive affect elicitation (using a short video clip) prior to exercise would have an additive effect on affect during acute exercise. 


\subsection{Method}

\subsection{Study Design and Participants}

This study was approved by the institutional review board at the University of Mississippi. As similarly utilized in other priming-related studies [43], we employed a purposive sampling of 30 young adults aged 18-40 years. It was not clear how the exercise-related priming effect may apply across age ranges, hence we attempted to restrict recruitment to young adults for this pilot study. Furthermore, utilizing the Physical Activity Readiness Questionnaire (PAR-Q), participants were excluded if they responded affirmatively to any of the seven items. Additional exclusionary criteria were pregnancy and any reported head trauma within the preceding thirty-day period. It is well established that memory deficits are common early after head trauma and disabling complaints like forgetfulness and learning problems can be persistent after initial injury in varying populations [44-46]. Furthermore, studies that have investigated head trauma have revealed that mild traumatic brain injury (MTBI) is associated with lower declarative memory performance [47].

Using power analysis software $G^{*}$ Power 3 [48], a sample size of 30 was sufficient to detect a significant difference between two paired groups at an $\alpha$ of 0.05 , power 0.80 , and effect size (d) of 0.47 . Similar effect size estimates have been reported in other related research [35]. Using a within-subject design, individuals participated in two conditions, one week apart in a counter-balanced order. Condition 1 involved positive affect elicitation prior to exercise, while there was no affect-elicitation in condition 2 (control).

Participants were instructed not to exercise within five hours prior to the scheduled lab visit [49] or use caffeine within three hours [50]. To minimize hunger-induced mood effects, they were also instructed to have a meal within four hours of their scheduled visit but not within the preceding one hour. Both conditions were conducted by the same investigator, in the same lab space, at approximately the same time of day, and participants were instructed to wear comfortable (preferably identical) clothing for the two visits. Maintaining similar environments at both testing periods was aimed at limiting potential influences of the exercise environment on affect. Participants completed surveys on demographic information and habitual physical activity was assessed using the Physical Activity as a Vital Sign questionnaire [51,52].

Participation involved watching a five-minute video, as well as walking on a treadmill at a self-selected brisk pace for ten minutes. Notably, self-selected speed was expected to vary based on individual characteristics, such as stride length, as well as individual preference. The same within-subject walking pace was maintained at both visits (participants were aware of the identical walking pace at both visits). That is, the selected brisk pace chosen at the first visit was recorded and re-used at the second visit. Affect was assessed at baseline (before video) and during the brisk walk (at minute five; midpoint). Weight and height measurements were taken at the end of the first visit. These measurements were left to the end of the visit to control for any potential influence of weight assessment on affect.

\subsection{Self-Selected Brisk Walking Pace}

A self-selected pace was chosen to allow for potential selection of similar relative exercise intensities. Additionally, self-selected walking intensity is thought to be more likely to generate a positive affective experience when compared to imposed intensities [53]. Participants were instructed as follows: "Please select a speed you would like to exercise at for ten minutes. Please try and stay at this speed for the entire ten minutes. Your selected speed should be at a brisk walking pace, as if you were late for catching the bus". At the end of the exercise bout, rating of perceived exertion (RPE) was evaluated using a 6-20 Borg scale [54,55]. 


\subsection{Positive Video}

A five-minute excerpt from a YouTube video of drunk people falling was utilized as a humorous stimulus [56]. Similar visual content has been shown to evoke humor [57]. This video was selected as our previous work with When Harry met Sally [38,42] among our demographic group (primarily college students) generated variable affective responses [58]. As a manipulation check, participants completed an affective circumplex assessment [59] before and immediately after the video. Using this instrument, on a scale of 0-100, participants self-reported their present-state "amusement" level, with higher scores indicating greater amusement. The mean (SE) baseline and post-video amusement scores, respectively, were $28.37 \pm 4.81$ and $37.50 \pm 4.99(p<0.01)$. This suggests that the video indeed elicited the target emotion (humor), demonstrating some evidence of content validity in our sample. Participants were equipped with headphones, seated in front of a 22-inch screen, and could adjust the preset volume if needed.

\subsection{Assessment of Exercise-Related Affect}

The feeling scale [60] and felt arousal scale [61] were used to assess the affective response to the bout of exercise. The combination of both scales was intended to examine the affective response in a dimensional manner, inclusive of both valence (feeling scale) and activation (felt arousal scale). The feeling scale requires individuals to rate how they feel "at the present moment", from -5 (very bad) to +5 (very good). The felt arousal scale asks individuals to rate how "worked-up" they feel, from 1 (low arousal) to 6 (high arousal).

\subsection{Statistical Analyses}

Statistical analyses were computed using IBM SPSS Statistics for Windows, Version 22.0 (Armonk, NY: IBM Corp). We used 2 (condition; priming versus no priming) $\times 2$ (time; pre- versus mid-exercise) repeated measures ANOVAs to compare affective valence and activation ratings during priming and control conditions, at baseline and during exercise. Statistical significance was set at $\alpha=0.05$.

\subsection{Results}

Characteristics of the sample are shown in Table 1. Among the 30 participating adults, the mean (SE: \pm ) age was $22.50 \pm 0.67$ years, $53 \%$ were male, and $60 \%$ identified as non-Hispanic white. The mean body mass index (BMI) was $25.75 \pm 0.74 \mathrm{~kg} / \mathrm{m}^{2}$ and on average, participants reported engaging in $187.5 \pm 34.05$ minutes/week of moderate-to-vigorous physical activity. The average walking speed was $3.61 \pm 0.15$ miles per hour. The rated perceived exertion of $9.23 \pm 0.31$ and $9.47 \pm 0.31$ for the priming and control conditions, respectively, were not significantly different $(p=0.34)$.

Table 1. Demographic and Exercise-related Characteristics—Mean (SE) and Proportions.

\begin{tabular}{ccc}
\hline & Experiment 1 & Experiment 3 \\
\hline Age & $22.50(0.67)$ & $21.00(0.25)$ \\
Gender (female) & $47 \%$ & $70 \%$ \\
Non-Hispanic White & $60 \%$ & $70 \%$ \\
Habitual PA (MVPA minutes/week) & $187.50(34.05)$ & $231.83(57.31)$ \\
Body Mass Index $\left(\mathrm{kg} / \mathrm{m}^{2}\right)$ & $25.75(0.74)$ & $25.83(0.97)$ \\
Walking Speed (MPH) at both visits & $3.61(0.15)$ & $3.54(0.06)$ \\
Rated Perceived Exertion at Condition 1 (priming condition) & $9.23(0.31)$ & $9.87(0.36)$ \\
Rated Perceived Exertion at Condition 2 (control condition) & $9.47(0.31)$ & $10.13(0.34)$ \\
\hline
\end{tabular}

MVPA = moderate-to-vigorous physical activity; $\mathrm{MPH}=$ miles per hour.

Table 2 displays the mean affective valence scores at baseline and intra-exercise for both the priming and control conditions. The mean valence at baseline for the priming condition was 2.70 , with 
a mean valence of 3.20 during the exercise bout; thus, the mean change in valence for the priming condition was 0.50 . In the control condition, the mean valence at baseline was 3.07 , with a mean valence of 3.2 during the exercise bout; thus, the mean change in valence for the control condition was 0.13 . Using a 2 (condition; priming versus no priming) $\times 2$ (time; pre- versus mid-exercise) repeated measures ANOVA, the slopes of the pre-to-during exercise valence ratings for both conditions were marginally different $(\mathrm{F}=3.55 ; p=0.07)$. This is illustrated in Figure A1.

Table 2. Mean (SE) of affective valence and activation scores during Condition 1 (priming) and Condition 2 (control) for Experiment 1.

\begin{tabular}{ccccc}
\hline & $\begin{array}{c}\text { Condition 1 } \\
\text { Valence }\end{array}$ & $\begin{array}{c}\text { Condition 2 } \\
\text { Valence }\end{array}$ & $\begin{array}{c}\text { Condition 1 } \\
\text { Activation }\end{array}$ & $\begin{array}{c}\text { Condition 2 } \\
\text { Activation }\end{array}$ \\
\hline Baseline & $2.70(0.19)$ & $3.07(0.21)$ & $2.63(0.19)$ & $2.83(0.20)$ \\
During Exercise & $3.20(0.16)$ & $3.20(0.21)$ & $3.50(0.19)$ & $3.30(0.20)$ \\
Change & $0.50(0.12)$ & $0.13(0.14)$ & $0.87(0.16)$ & $0.47(0.21)$ \\
\hline
\end{tabular}

Valence was rated on a scale of -5 to +5 , and activation was rated on a scale of $0-6$. The slopes of the pre-to-during exercise valence and activation ratings for both conditions were marginally different $(p=0.07)$.

Using a 2 (condition; priming versus no priming) $\times 2$ (time; pre- versus mid-exercise) repeated measures ANOVA, the slopes of the pre-to-during exercise activation ratings for both conditions were marginally different $(\mathrm{F}=3.55 ; p=0.07)$. This is illustrated in Figure A2.

\subsection{Discussion}

In this pilot experiment, we examined the utility of video-based positive affective priming on intra-exercise valence and activation. We examined the change in valence and activation during and before exercise. On average, there was a marginally greater pre-to-mid exercise increase in valence, as well as activation when the priming video was viewed. Notably, although the change scores (slopes) were somewhat different, the intra-exercise valence and activation scores were similar for both conditions. Hence, although the directionality of these findings appeared to be interesting, we exercise caution in interpreting these findings. In subsequent experiments, we further investigated the potential for positive affective outcomes when utilizing video-based affective priming.

To ascertain the veracity of these findings, we conducted a replication of this study, addressing some of the limitations of this pilot experiment. In Experiment 2, we compared the affect-elicitation properties of self-selected and imposed video clips (could we induce a higher affective stimulus using self-selected video clips?). In Experiment 3, we re-investigated the potential affective benefit of priming, while including a neutral video during the control condition to attenuate potential demand characteristics (was the priming effect caused by watching a video irrespective of content?), and a positive video-only condition to investigate possible carryover effects (was the post-exercise affect a lingering result of the video clip versus additive video-plus-exercise-related affect, as proposed?).

\section{Experiment II}

\subsection{Purpose}

With respect to the humorous video clip used in Experiment 1, although this video (of drunk people falling) appeared to elicit the targeted positive affect, we were concerned about the potency of the stimulus. To illustrate, although the pre- to post-amusement score increased statistically, it only increased by 9.2 units (on a scale of $0-100$ ), which may be perceived as a marginal increase. Hence, we intended to elicit a stronger response with more targeted clip selection in the subsequent experiments. Basic emotions, such as humor, may be variable among individuals based on social experiences $[40,57]$. For example, participants who had personal or vicarious experiences with alcohol-use problems expressed less favorable feedback on the video used in Experiment 1. 
Hence, in our follow-up experiment (Experiment 2), we examined the affective experience associated with a self-selected video, compared to (validated) imposed videos. Although imposed clips may allow for replicability, our previous work [62] suggests that using self-selected video content while exercising results in a greater reported positive affective experience compared to imposed video clips. Furthermore, we intended to examine potential video-related demand characteristics and carryover effects in a third experiment. This would entail the use of a neutral video clip and the repetitive use of a positive video. Therefore, in Experiment 2, we also identified an appropriate neutral video clip, and explored the affective-eliciting property of a positive film clip with repeated use.

\subsection{Method}

\subsection{Study Design and Participants}

This study was approved by the institutional review board at the University of Mississippi. Adapting film validation procedures described elsewhere [37], the study involved a purposive sampling of 18 adults aged 18-40 years. Participants completed four conditions. Condition 1 involved watching an imposed neutral video clip as part of a group. Condition 2 involved watching an imposed positive video clip as part of a group. Condition 3 involved watching a self-selected positive video individually. Condition 4 involved watching again the same imposed positive video that was seen in condition 1, as part of a group. The goal of these four conditions was to test a previously validated neutral video (condition 1), to compare the self-selected clip with the imposed positive clip (conditions 2 and 3 , respectively), and to assess the test-retest reliability of the imposed positive clip (by comparing conditions 2 and 4$)$.

Participants completed surveys to assess demographic characteristics, feelings about the video clip, and to intermittently ascertain their mood. Participants were given similar instructions as with Experiment 1 .

\subsection{Positive and Neutral Videos}

A previously validated neutral video (Blue-escalator) was selected for condition $1[38,63]$. For the imposed positive clip, an excerpt from The Office, as described in a recent affect film database by Gilman et al., was chosen [38]. For self-selected video clips, participants were asked to provide a four-to-five-minute video excerpt they found funny, as similarly utilized elsewhere [62].

\subsection{Assessment of Affect}

The feeling scale [60] and felt arousal scale [61] were used to assess the affective state prior to and after the film clip. A post-film questionnaire was used to examine the affect-eliciting properties of the selected videos [37]. This survey required participants to rate how they felt regarding 18 specific emotions (such as amusement, joy, disgust) while watching the film, on a scale of 0 (not at all/none) to 8 (extremely/a great deal). Additionally, participants were asked to report an overall pleasantness rating on a scale of 0 (unpleasant) to 8 (pleasant), if they had seen the film clip before (yes/no), and if they closed their eyes during any of the scenes (yes/no). Participants also completed an affective circumplex assessment [59] before and immediately after each video.

\subsection{Statistical Analyses}

For the selection of a neutral video, a threshold mean rating of $<2.5$ on a scale of 7 for all emotions of interest has been utilized elsewhere, with ratings $>3$ considered to be beyond neutral [38]. Using the post-film questionnaire scored on a range of $0-8$ [37], we adapted a threshold value of $\leq 3$ on all emotions of interest as acceptable for a neutral video clip.

The success index of the examined imposed and self-selected positive videos in eliciting a positive affective state of amusement was determined based on intensity and discreteness ratings, as similarly 
utilized elsewhere [38]. Using the post-film questionnaire, intensity was calculated as the mean amusement rating for each video. The amusement discreteness value (hit rate) was calculated as the percentage of participants rating amusement at least one point above all non-target (negative) emotions. The success index was the sum of the standardized score (z-score) of intensity and discreteness for imposed and self-selected clips. Paired t-tests were also used to compare the emotional ratings of self-selected and imposed clips $(\alpha=0.05)$. The slope of the pre-to-post video amusement, valence, and activation ratings were also compared between self-selected and imposed video clips using a 2 (condition) $\times 2$ (time) repeated measures ANOVA $(\alpha=0.05)$.

The test-retest reliability of the positive video clip was calculated as the intraclass correlation (ICC) between the amusement change scores from baseline to post-video at both time points, and for all emotions using the post-film questionnaire at both time points $(\alpha=0.05)$.

\subsection{Results}

Among the 18 participating adults, the mean (SE) age was $22.18 \pm 0.18$ years, $61 \%$ were female, and $56 \%$ identified as non-Hispanic white. On average, participants reported engaging in $208 \pm 33.25$ minutes/week of moderate-to-vigorous physical activity.

The mean rating of most emotions for the neutral video was $\leq 3$. Means (SE: \pm ) for emotions above this threshold were $3.78 \pm 0.19$ for interest and $5.94 \pm 0.40$ for confusion. The overall pleasantness rating was $3.72 \pm 0.32$.

The self-selected positive video had an amusement intensity rating of $7.11 \pm 0.18$, while the intensity rating for the imposed video clip was $6.94 \pm 0.27$. These were not statistically different $(p=0.62)$. The self-selected video also had an amusement discreteness rating of $100 \%$ as compared to the imposed video clip (94.44\%). Hence, the self-selected video clip had a higher success index (+2). Using paired $\mathrm{t}$-tests comparing ratings of all emotions for the self-selected and imposed video, the mean rating of pride was higher $(p=0.02)$ for the self-selected clip, at $2.33 \pm 0.62$, when compared to the imposed video at $0.83 \pm 0.37$. All other 17 emotions were similarly rated. The slope of the pre-to-post video amusement, valence, and activation ratings were not significantly different between the self-selected and imposed video clips ( $p=0.51,0.45$, and 0.73, respectively). See Figure A3 in the Appendix 5 .

The ICC ( $95 \%$ C.I.) between the amusement change scores from baseline to post-video at both time points was $0.80(0.29-0.93)$ and for all emotions was $0.39(0.18-0.65)$. These ICCs were statistically significant $(p<0.01)$.

\subsection{Discussion}

The ratings of most emotions on the examined neutral video clip were below the preset threshold. However, there were above-threshold ratings for interest and confusion. A moderate rating of interest with neutral clips is thought to be acceptable as it averts the elicitation of boredom [38]. Also, the ratings for confusion were unsurprising, as participants were given limited information on the nature of the video, to attenuate the potential influence of social desirability. Furthermore, the overall pleasantness rating of 3.7 on a scale of $0-8$ was at about the midpoint (neither pleasant nor unpleasant), which was the target. This video was therefore deemed appropriate for use as the neutral clip in Experiment 3.

Although the success index was higher for the self-selected video, there were similar emotion-eliciting properties with both (imposed and self-selected) priming video options, based on statistical comparisons of 18 emotional ratings on the post-film questionnaire, as well as pre-post change scores (slopes) on the feeling scale, felt arousal, and amusement (affective circumplex) scale. Hence, the use of either video options would be acceptable for our purpose. However, the imposed video may allow for standardization [37]. We established some evidence of test-retest reliability with this imposed video. Hence, this previously validated video was used as the priming video in Experiment 3 . A noteworthy potential limitation in this validation study is the methodological difference in the assessment of standardized clips (group-based) versus self-selected clips (individually rated). Although the experimenters found the synchronized timing of rating for standardized clips potentially 
useful, the extent to which group dynamics may have influenced the rating of the standardized clip remains unclear. Future work with similar studies could attempt to further tease this out.

\section{Experiment III}

\subsection{Purpose}

The pilot experiment on the potential effects of priming on intra-exercise affect showed marginal increases in pre-to-mid exercise affective valence as well as affective activation when the priming video was viewed. However, in Experiment 1, we were concerned about possible demand characteristics from viewing a video in the priming condition and no video in the control condition. It may be uncertain whether the changes in affective evaluation were attributable to the positive content or alternatively were due to the mere viewing of a video. Hence, for Experiment 3, we utilized the neutral video examined in Experiment 2 during the control condition.

To examine whether the positive intra-exercise affect was a carryover effect of the pre-exercise video, we included a video-only condition in Experiment 3. In this condition, participants watched a video inducing positive affect, but did not exercise. We subsequently compared the slope of affective valence and activation change from post-video to intra-exercise between the priming (video and exercise) condition and the video-only condition. Per Experiment 2, the repetitive use of the same positive film clip appears to be acceptable.

\subsection{Method}

\subsection{Study Design and Participants}

This study was approved by the institutional review board at the University of Mississippi. As utilized in experiment 1, we employed a purposive sampling of 30 adults aged 18-40 years who met exclusionary criteria. Participants were primarily recruited from Exercise Science classes in our university. Using a within-subject design, individuals participated in three conditions in a counter-balanced order. Condition 1 involved positive affect elicitation prior to exercise (priming condition), condition 2 involved viewing a neutral video prior to exercise (control condition), and condition 3 involved viewing a positive video with no exercise (video-only condition). Exclusionary criteria were the same as with Experiment 1. Participants were also given the same instructions as with Experiment 1 and all three conditions were conducted similarly.

For the priming and control conditions, participation involved watching a positive or neutral video, as well as walking on a treadmill at a self-selected brisk pace for ten minutes. The same within-subject walking pace was maintained for both conditions. During the video-only condition, participants were asked to watch a positive video and then read three neutral texts [64] at a leisurely pace over ten minutes. Our goal was to select an appropriate neutral stimulus without eliciting boredom (which could be anticipated from, alternatively, doing nothing). The selected neutral texts were previously validated and, notably, were also subjectively rated as neutral (or slightly pleasant) by participants in our study (see results section). Affect was assessed at baseline, post-video, and mid-exercise (or mid-text). Weight and height measurements were taken at the end of the first visit.

\subsection{Self-Selected Brisk Walking Pace}

As with Experiment 1, a self-selected pace was used to allow for the potential selection of similar relative exercise intensities. The walking protocol was similar to Experiment 1 . At the middle of the exercise bout, rating of perceived exertion (RPE) was evaluated using a 6-20 Borg scale [54]. Heart rate measurements were also assessed at baseline, post-video, mid-exercise, and post-exercise, using a Polar F1 heart rate monitor. 


\subsection{Positive and Neutral Videos}

Based on results from Experiment 2, an excerpt from The Office [38] was used as the priming stimulus, and the neutral video Blue-escalator $[38,63]$ was also selected for the control condition. Participants were equipped with headphones, seated in front of a 22-inch screen and could adjust the preset volume if needed.

\subsection{Assessment of Affect}

Affective valence was assessed using the empirical valance scale [65]. The empirical valence scale (EVS) is a horizontal numeric scale with ratings in the range of -100 (most unpleasant) to +100 (most pleasant imaginable), anchored at 0 (neutral). The EVS rating therefore should more closely approximate an interval-like scale of measurement, which properly allows for stronger inferences regarding the quantitative magnitude of differences that exist between ratings. Furthermore, these anchors of maximal pleasure (pleasant and unpleasant) will help to potentially assess particularly intense experiences more accurately compared to other Likert-type scales (Feeling Scale). Thus, this scale offers the advantage of potentially increased sensitivity and ecological validity as compared to other self-report measures of affective valence [65]. The felt arousal scale [61] was used to assess activation. Amusement ratings were measured using the affective circumplex assessment [59] before and immediately after the videos were viewed, as well as post-exercise. Adapting the post-film questionnaire [37], a post-text questionnaire was administered after the neutral texts were read.

\subsection{Statistical Analyses}

Statistical analyses were computed using IBM SPSS Statistics for Windows, Version 22.0 (Armonk, NY: IBM Corp). We performed descriptive evaluations of demographic characteristics, rated perceived exertion mid-exercise, amusement ratings, and heart rate changes over time. The emotional ratings for the neutral text were also examined, adapting a threshold value of $\leq 3$, as similarly utilized in Experiment 2.

Repeated measures ANOVAs were used to examine the slopes of change for valence/activation ratings during the three conditions. Significant interactions were followed by simple effects analyses [66]. Statistical significance was set at $\alpha=0.05$.

\subsection{Results}

Amusement ratings spiked after the video was seen and returned to baseline after exercise. This trend was similar both times when the positive video was utilized. On the other hand, amusement ratings remained close to baseline for the control condition (see Figure A4). Heart rate trends were similar for both exercise conditions and stayed close to baseline for the video-only condition (see Figure A5). The mean rating of most emotions on the post-text questionnaire was $\leq 3$. Means (SE) for emotions above this threshold were $3.70 \pm 0.43$ for amusement, $4.00 \pm 0.40$ for interest, $3.07 \pm 0.43$ for joy, and $4.66 \pm 0.32$ for pleasantness.

Figure 1 displays the trend in affective valence ratings across time. There was a significant condition $\times$ time interaction $(F=5.23 ; p=0.002)$. The $\eta^{2}$ p was 0.15 . For the priming condition, valence significantly increased from baseline to post-video $(p=0.04)$ and stayed the same at mid-exercise $(p=0.70)$. During the control condition, valence stayed the same at baseline and post-neutral video $(p=0.11)$ and was marginally increased at mid-exercise $(p=0.07)$. Notably, the slope of valence change from post-video to mid-exercise was not different between the priming and control conditions $(p=0.24)$. For the video-only condition, valence significantly increased from baseline to post-video $(p=0.04)$ and was significantly lower mid-neutral text $(p<0.01)$.

Figure 2 displays the trend in affective activation ratings over time. There was a significant condition $\times$ time interaction $(\mathrm{F}=13.37 ; p<0.01)$. The $\eta^{2} \mathrm{p}$ was 0.32 . For the priming condition, activation significantly increased from baseline to post-video $(p=0.01)$ and was further increased at mid-exercise 
$(p<0.01)$. During the control condition, activation stayed the same at baseline and post-neutral video $(p=0.65)$ and was significantly increased at mid-exercise $(p<0.01)$. Notably, the slope of activation change from post-video to mid-exercise was greater for the control condition, compared to the priming condition $(p=0.03)$. For the video-only condition, activation significantly increased from baseline to post-video $(p<0.01)$ and was significantly lower mid-neutral text $(p<0.01)$.

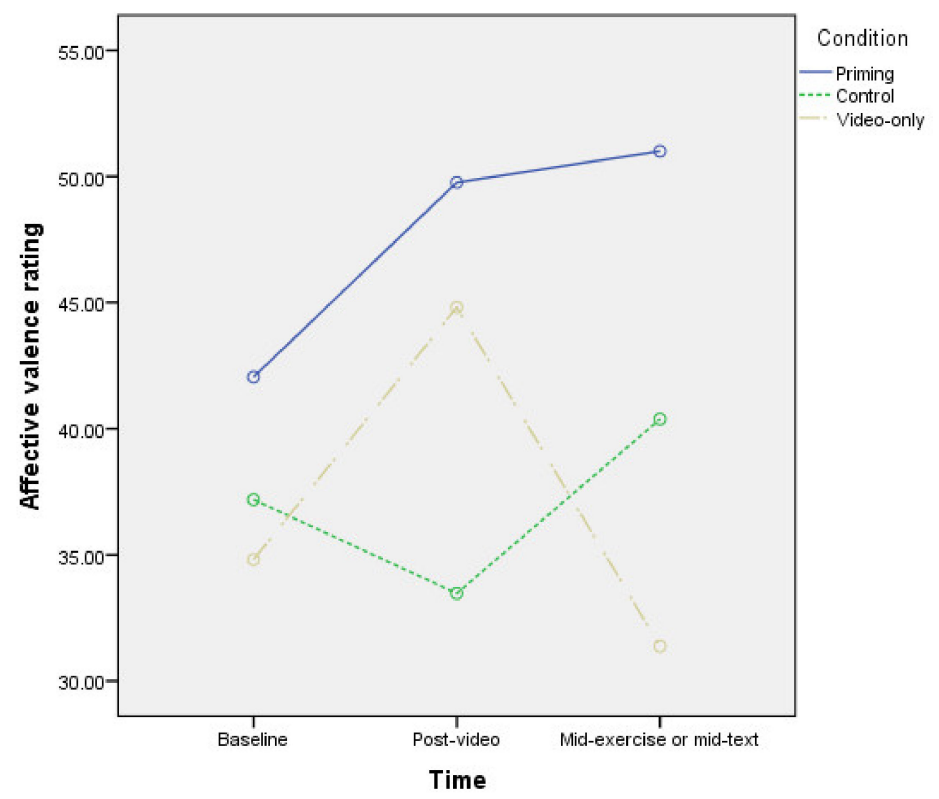

Figure 1. Trend in affective valence ratings over time (Experiment 3 ). There was a significant condition $\times$ time interaction $(F=5.23 ; p=0.002)$. The $\eta^{2} p$ was 0.15 . For the priming condition, valence significantly increased from baseline to post-video $(p=0.04)$ and stayed the same at mid-exercise $(p=0.70)$. During the control condition, valence stayed the same at baseline and post-neutral video $(p=0.11)$ and was marginally increased at mid-exercise $(p=0.07)$. Notably, the slope of valence change from post-video to mid-exercise was not different between the priming and control conditions $(p=0.24)$. For the video-only condition, valence significantly increased from baseline to post-video $(p=0.04)$ and was significantly lower mid-neutral text $(p<0.01)$.

Table 3 displays the mean (SE) valence and activation ratings over time for all conditions. There were no baseline differences in valence and activation between all three conditions $(p=0.42$ and 0.71 , respectively). The post-video and intra-exercise valences were significantly higher in the priming condition when compared to the control $(p \leq 0.01)$. While the post-video valence ratings were not statistically different $(p=0.17)$ between the priming and video-only conditions, the intra-task valence was significantly lower $(p<0.01)$ in the video-only condition. When considering activation ratings, the post-video activation was marginally higher in the priming condition when compared to the control $(p=0.06)$. However, there was no differences in the intra-exercise ratings $(p=0.86)$. Also, while the post-video activation ratings were not statistically different $(p=0.43)$ between the priming and video-only conditions, the intra-task activation was significantly lower $(p<0.01)$ in the video-only condition. 


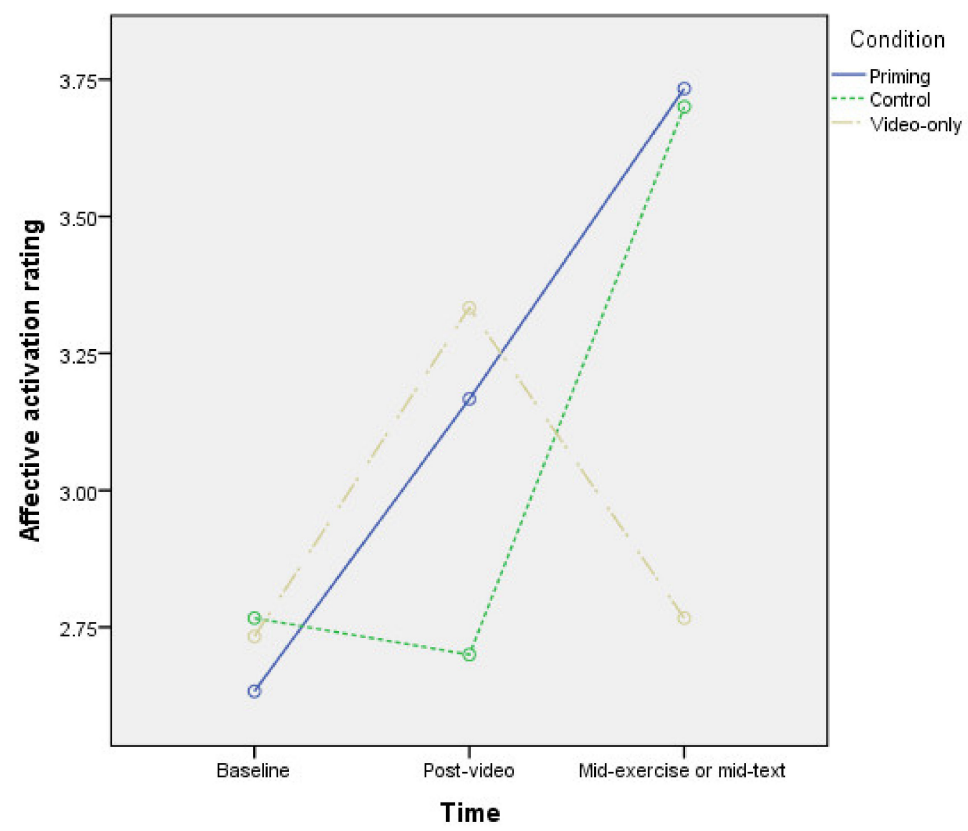

Figure 2. Trend in affective activation ratings over time (Experiment 3 ). There was a significant condition $\times$ time interaction $(F=13.37 ; p<0.01)$. The $\eta^{2} p$ was 0.32 . For the priming condition, activation significantly increased from baseline to post-video $(p=0.01)$ and was further increased at mid-exercise $(p<0.01)$. During the control condition, activation stayed the same at baseline and post-neutral video $(p=0.65)$ and was significantly increased at mid-exercise $(p<0.01)$. Notably, the slope of activation change from post-video to mid-exercise was greater for the control condition, compared to the priming condition $(p=0.03)$. For the video-only condition, activation significantly increased from baseline to post-video $(p<0.01)$ and was significantly lower mid-neutral text $(p<0.01)$.

Table 3. Mean (SE) of affective valence and activation scores during Condition 1 (priming), Condition 2 (control), and Condition 3 (video-only) for Experiment 3.

\begin{tabular}{ccccccc}
\hline & \multicolumn{3}{c}{$\begin{array}{c}\text { Affective } \\
\text { Valence }\end{array}$} & \multicolumn{3}{c}{$\begin{array}{c}\text { Affective } \\
\text { Activation }\end{array}$} \\
& Priming & Control & Video-only & Priming & Control & Video-only \\
Baseline & 42.05 & 37.19 & 34.81 & 2.63 & 2.77 & 2.73 \\
& $(3.95)$ & $(3.78)$ & $(5.21)$ & $(0.19)$ & $(0.22)$ & $(0.23)$ \\
Post-video & 49.76 & 33.48 & 44.81 & 3.17 & 2.70 & 3.33 \\
Intra-task & $(3.63)$ & $(4.69)$ & $(4.24)$ & $(0.17)$ & $(.22)$ & $(0.22)$ \\
(exercise or text) & 51.00 & 40.38 & 31.38 & 3.73 & 3.70 & 2.77 \\
\hline
\end{tabular}

Valence was rated on a scale of -100 to +100 , and activation was rated on a scale of $0-6$. For all three conditions, there were no baseline differences in affective valence and activation $(p=0.42$ and 0.71 , respectively). The post-video and intra-exercise valences were significantly higher in the priming condition when compared to the control $(p \leq 0.01)$. While the post-video valence ratings were not statistically different $(p=0.17)$ between the priming and video-only conditions, the intra-task valence was significantly lower $(p<0.01)$ in the video-only condition. When considering activation ratings, the post-video activation was marginally higher in the priming condition when compared to the control $(p=0.06)$. However, there were no differences in the intra-exercise ratings $(p=0.86)$. Also, while the post-video activation ratings were not statistically different $(p=0.43)$ between the priming and video-only conditions, the intra-task activation was significantly lower $(p<0.01)$ in the video-only condition.

\subsection{Discussion}

In assessing intervention fidelity, the positive and neutral videos, as well as the neutral text, elicited the desired affective response. The exercise stimulus was comparable between the priming and control conditions, as seen with examination of the perceived exertion ratings and changes in heart 
rate over time. The directionality of changes in affective valence and activation ratings also suggests appropriate affect-eliciting properties with both videos and the neutral text, as well as with exercise.

There was a significant effect of priming on affective valence, as the post-video valence ratings were higher in the priming condition when compared to the control. When compared to the control and video-only conditions, the highest affective valence at task (exercise or reading neutral text) mid-point was seen during the exercise-priming condition. This suggests that the changes in affective valence seen herein, as well as with Experiment 1, were neither a result of video-related demand characteristics nor a carry-over effect from the funny video clip alone.

Although there was a significant priming effect on affective activation, there was a higher rate of change in activation between the post-video and mid-exercise timepoints for the control condition, compared to the priming condition. Consequently, the activation ratings at mid-exercise were similar in the priming and control conditions. This suggests that the degree of activation may be more directly related to the intensity of the exercise, which was the same in both conditions. Although the increase in activation was similar in the priming and video-only conditions, exercise was seen to further increase the activation, while reading the neutral text lowered activation towards baseline. Hence, video-based priming may be useful to kick-start increases in activation prior to initiation of exercise.

\section{General Discussion}

The importance of physical activity in attenuating risk for cardiovascular disease (CVD) and diabetes is well-established $[67,68]$. However, despite these benefits, a significant proportion of U.S. adults do not meet physical activity guidelines $[19,20]$, with notable health-related $[67,68]$ and economic consequences [69]. Physical activity enjoyment is thought to be an important correlate for physical activity behavior [70]. Individuals who experience strong positive affective responses to physical activity may be more likely to be habitually active, compared to individuals who experience less pleasurable exercise-related feelings [70]. Previous research suggests that emotions may influence intrinsic motivation and goal pursuit [33]. Our previous work also suggests that induction of sedentary behavior among habitually active adults may result in adverse psychological outcomes [71] and short (e.g., $5 \mathrm{~min}$ ) bouts of exercise induce positive psychological outcomes [72]. There are variable findings with exercise intensity and affect, and this may be related to individual preference [73], as well as physiological variables, such as ventilation, oxygen uptake, lactate concentration, and core body temperature during exercise [17]. Methods to accentuate a positive experience with exercise need to be further explored, in view of the extant physical inactivity level [18]. Although apparently intuitive, there is a dearth of knowledge on the potential role of affective priming on intra-exercise affect. The paucity of research in this domain was the motivation for our novel paradigm.

In the present experiments, we examined the utility of video-based positive affective priming on intra-exercise on valence and activation. We compared the reported valence as well as activation during exercise as compared to before exercise. We found some potential utility for this affective priming paradigm for enhancing the peak of valence ratings at mid-exercise, as well as for initiating changes in activation prior to the onset of exercise. However, the peak of intra-exercise activation seems to be unaffected by the priming stimulus. Put together, the apparent increase in peak intra-exercise valence while at the same activation level seen with priming may be described as movement along the anxiety-enthusiasm axis of the affective circumplex model [7]. This movement may be beneficial, especially for neo-exercisers, as anxiety could be a perceived barrier to exercise adoption and adherence $[74,75]$.

One theoretical method by which this movement to the right (towards enthusiasm) on the affective circumplex model could be beneficial is through the creation of favorable affect-related memory traces [6]. The ART describes the relationship between automatic affective evaluations and the tendency towards exercise behavior [6]. The use of prime-based affective stimulation may alter automatic associations, and hence the encoded affect associated with exercise, potentially increasing the likelihood of exercise behavior. 
A notable limitation of this study is the uncertain generalizability of findings, as one potential method of affect accentuation for a ten-minute bout of aerobic exercise was examined in a predominantly young, active college student population. We also evaluated the affective state at one time-point during exercise, which may not represent the entire scope of affective changes associated with a bout of exercise. Importantly, though, affect during exercise is a critical temporal period that appears to predict future engagement in exercise [5]. Strengths include the novelty, triphasic experimental approach, and potential application for physical activity program design. In view of the novelty of this paradigm, future replication studies are needed across other demographic (such as age and activity level), geographical (non-college), and environmental (such as clinical rehabilitation) settings. Future work could explore the biological plausibility, as well as the potential role of subconscious priming [24] of affective responses on exercise adherence [26,76]. Future work may also attempt to examine other methods for affect accentuation, such as self-selected videos [62], videos based on telic-dominance [41,61], pictures, music, cognitive tasks, dyadic interaction, and primary reinforcement [37]. There is a need to explore the utility of priming across variable exercise intensities scaled to ventilatory threshold [6], exercise durations below or above 35 minutes [10], and exercise types, such as with resistance exercise [9]. Additionally, multi-componential assessment of the cognitive, experiential, physiological, and behavioral elements of emotion could yield further insights [37].

Summarily, to maximize the potential "feel-good" effect of exercise, consideration should be given to the use of affective priming techniques (such as a funny video clip), as our current research suggests that priming the affective state prior to exercise may be beneficial for enhancing intra-exercise affect, which is a key predictor of future exercise behavior. If future work, indeed, demonstrates a consistent priming effect on exercise hedonics, this could have important health promotion implications.

Author Contributions: Authors O.A. and P.L. were involved in the conceptualization of the study. Author O.A. collected the data, analyzed the data and prepared the initial draft of the manuscript. Author P.L. was involved in revising the manuscript. Author R.S. was involved in revising the manuscript per reviewer feedback. All authors have read and agreed to the published version of the manuscript.

Funding: This research received no external funding.

Conflicts of Interest: The authors declare no conflict of interest

\section{Appendix}

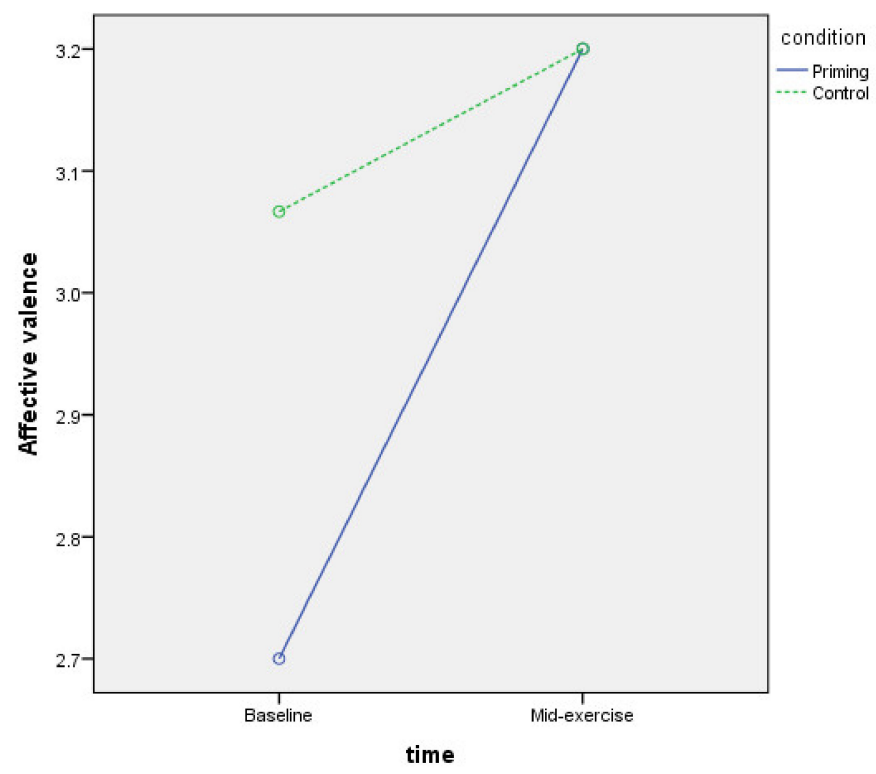

Figure A1. Affective valence ratings at baseline and mid-exercise for priming and control conditions (Experiment 1). Using a $2 \times 2$ repeated measures ANOVA, the slopes of the pre-to-during exercise valence ratings for both conditions were marginally different $(\mathrm{F}=3.55 ; p=0.07)$. 


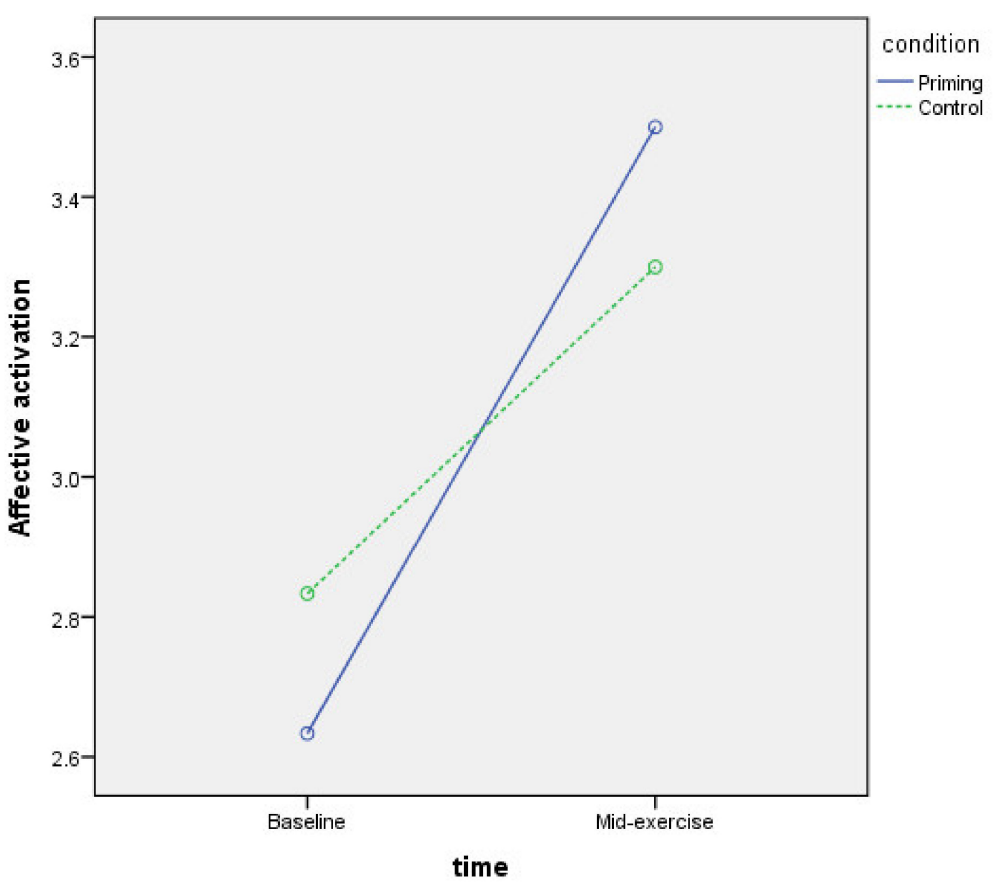

Figure A2. Affective activation ratings at baseline and mid-exercise for priming and control conditions (Experiment 1). Using a $2 \times 2$ repeated measures ANOVA, the slopes of the pre-to-during exercise activation ratings for both conditions were marginally different $(\mathrm{F}=3.55 ; p=0.07)$.

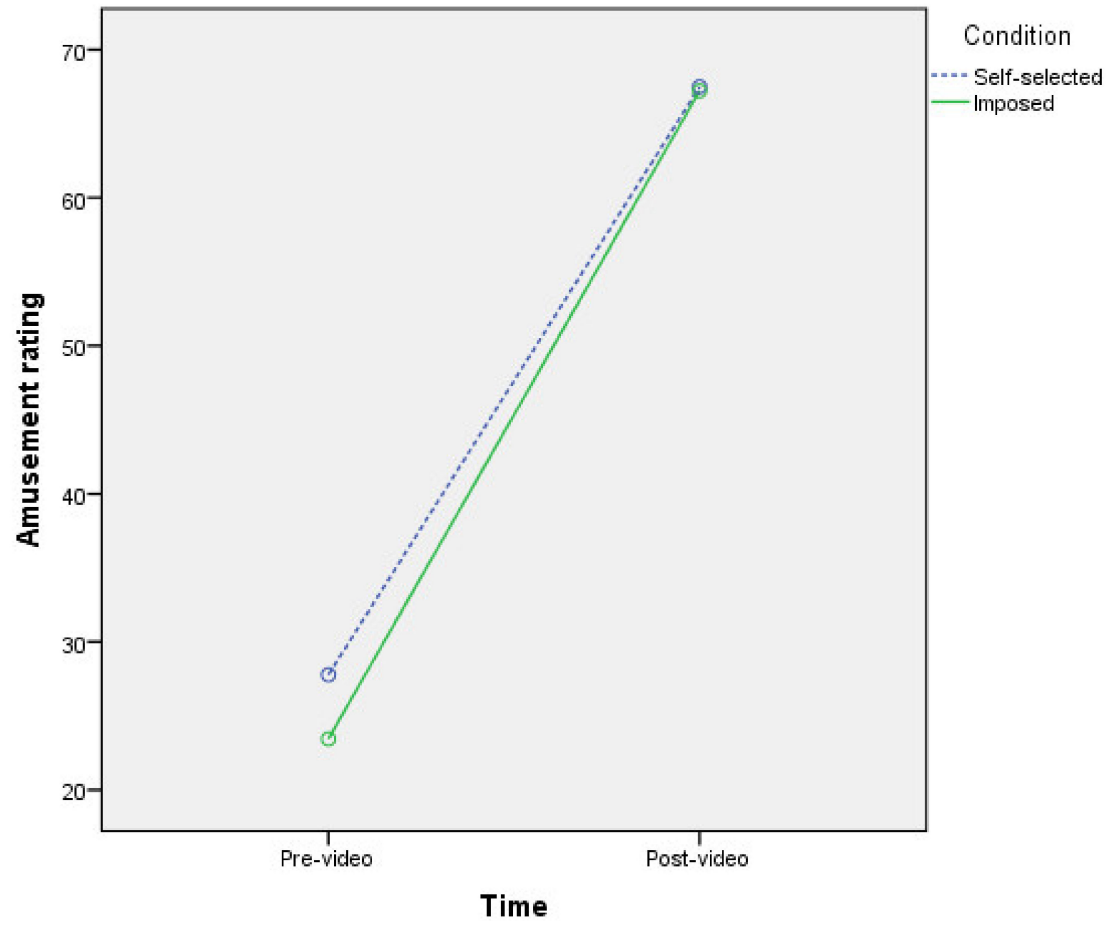

Figure A3. Graph of amusement ratings at baseline and post-video for self-selected and imposed video conditions. The slopes for self-selected and imposed positive video conditions were no different $(p=0.51)$. 


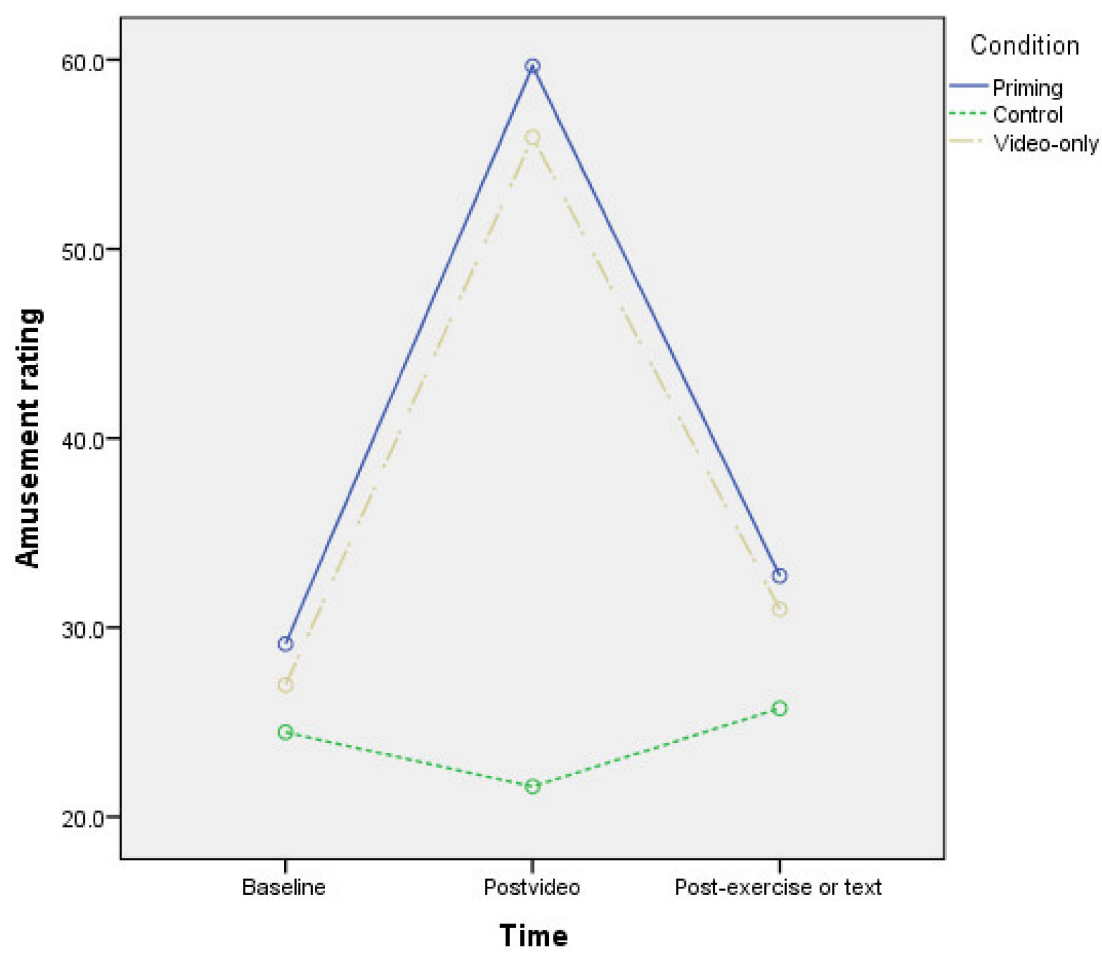

Figure A4. Graph of amusement ratings over time (Experiment 3). Amusement ratings spiked after the video was seen and returned to baseline after exercise. This trend was similar at both times when the positive video was utilized. On the other hand, amusement ratings remained close to baseline for the control condition.

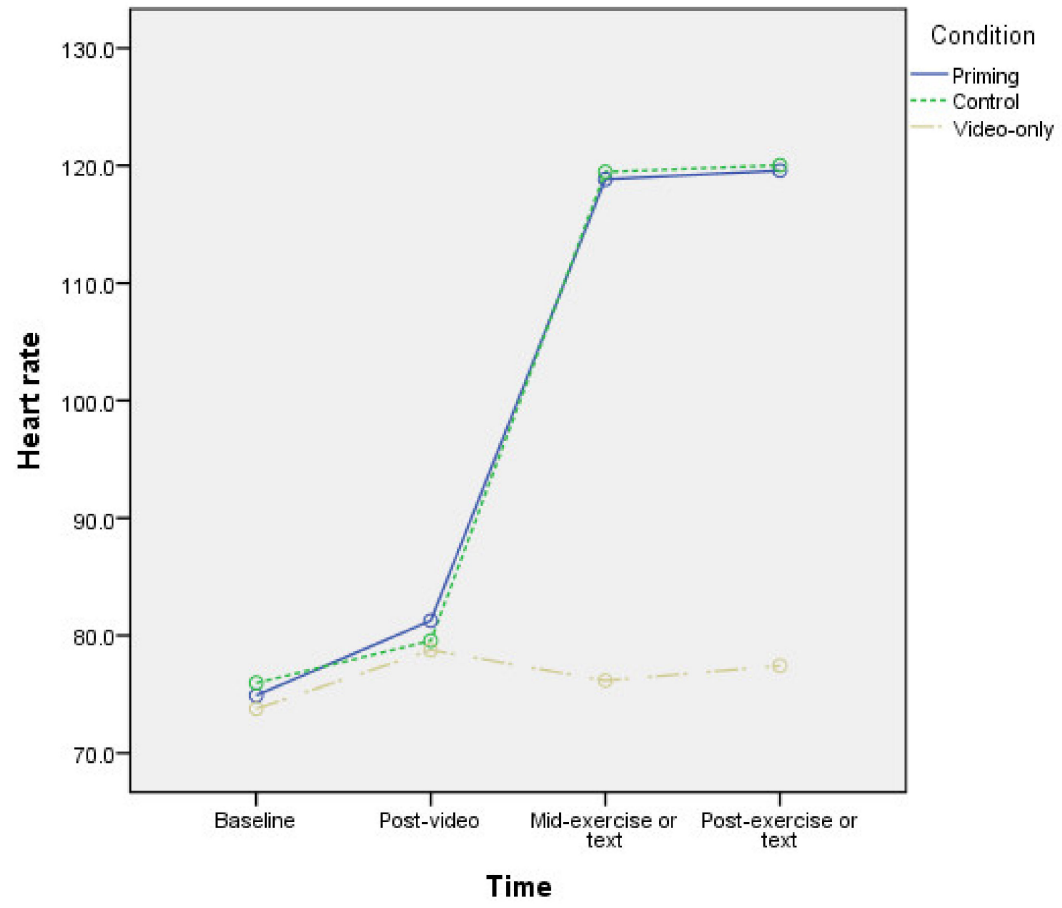

Figure A5. Graph of heart rate over time (Experiment 3). Heart rate trends were similar for both exercise conditions and stayed close to baseline for the video-only condition. 


\section{References}

1. Bauman, A.E.; Reis, R.S.; Sallis, J.F.; Wells, J.C.; Loos, R.J.; Martin, B.W.; Lancet Physical Activity Series Working Group. Correlates of physical activity: Why are some people physically active and others not? Lancet 2012, 380, 258-271. [CrossRef]

2. Kahn, E.B.; Ramsey, L.T.; Brownson, R.C.; Heath, G.W.; Howze, E.H.; Powell, K.E.; Stone, E.J.; Rajab, M.W.; Corso, P. The effectiveness of interventions to increase physical activity. A systematic review. Am. J. Prev. Med. 2002, 22, 73-107. [CrossRef]

3. Conn, V.S.; Sells, T.G.C. Effectiveness of interventions to increase physical activity among minority populations: An umbrella review. J. Natl. Med. Assoc. 2016, 108, 54-68. [CrossRef] [PubMed]

4. Plotnikoff, R.C.; Lubans, D.R.; Penfold, C.M.; Courneya, K.S. Testing the utility of three social-cognitive models for predicting objective and self-report physical activity in adults with type 2 diabetes. Br. J. Health Psychol. 2014, 19, 329-346. [CrossRef]

5. Rhodes, R.E.; Kates, A. Can the affective response to exercise predict future motives and physical activity behavior? A systematic review of published evidence. Ann. Behav. Med. 2015, 49, 715-731. [CrossRef]

6. Brand, R.; Ekkekakis, P. Affective-reflective theory of physical inactivity and exercise. Ger. J. Exerc. Sport Res. 2017, 48, 48-58. [CrossRef]

7. Warr, P.; Bindl, U.K.; Parker, S.K.; Inceoglu, I. Four-quadrant investigation of job-related affects and behaviours. Eur. J. Work Organ. Psychol. 2014, 23, 342-363. [CrossRef]

8. Ekkekakis, P.; Hall, E.E.; VanLanduyt, L.M.; Petruzzell, S.J. Walking in (affective) circles: Can short walks enhance affect? J. Behav. Med. 2000, 23, 245-275. [CrossRef]

9. Cavarretta, D.J.; Hall, E.E.; Bixby, W.R. The acute effects of resistance exercise on affect, anxiety, and mood-practical implications for designing resistance training programs. Int. Rev. Sport Exerc. Psychol. 2019, 12, 295-324. [CrossRef]

10. Reed, J.; Ones, D.S. The effect of acute aerobic exercise on positive activated affect: A meta-analysis. Psychol. Sport Exerc. 2006, 7, 477-514. [CrossRef]

11. Parfitt, G.; Hughes, S. The exercise intensity-affect relationship: Evidence and implications for exercise behavior. J. Exerc. Sci. Fitness 2009, 7, S34-S41. [CrossRef]

12. Ma, Q. Beneficial effects of moderate voluntary physical exercise and its biological mechanisms on brain health. Neurosci. Bull. 2008, 24, 265-270. [CrossRef] [PubMed]

13. Greenwood, B.N.; Fleshner, M. Exercise, stress resistance, and central serotonergic systems. Exerc. Sport Sci. Rev. 2011, 39, 140-149. [CrossRef] [PubMed]

14. Boecker, H.; Sprenger, T.; Spilker, M.E.; Henriksen, G.; Koppenhoefer, M.; Wagner, K.J.; Valet, M.; Berthele, A.; Tolle, T.R. The runner's high: Opioidergic mechanisms in the human brain. Cereb. Cortex 2008, 18, $2523-2531$. [CrossRef]

15. LeDoux, J. Sensory systems and emotion: A model of affective processing. Integr. Psychiatry 1986, 4, $245-247$.

16. Yeung, R.R. The acute effects of exercise on mood state. J. Psychosomatic Res. 1996, 40, 123-141. [CrossRef]

17. Ekkekakis, P. Pleasure and displeasure from the body: Perspectives from exercise. Cognit. Emot. 2003, 17, 213-239. [CrossRef]

18. Andersen, L.B.; Mota, J.; Di Pietro, L. Update on the global pandemic of physical inactivity. Lancet 2016, 388, 1255-1256. [CrossRef]

19. Tucker, J.M.; Welk, G.J.; Beyler, N.K. Physical activity in US adults: Compliance with the physical activity guidelines for Americans. Am. J. Prev. Med. 2011, 40, 454-461. [CrossRef]

20. Troiano, R.P.; Berrigan, D.; Dodd, K.W.; Masse, L.C.; Tilert, T.; McDowell, M. Physical activity in the United States measured by accelerometer. Med. Sci. Sports Exerc. 2008, 40, 181-188. [CrossRef]

21. Groves, P.; Thompson, R. Habituation: A dual-process theory. Psychol. Rev. 1970, 77, 419. [CrossRef] [PubMed]

22. Zenko, Z.; Ekkekakis, P.; Kavetsos, G. Changing minds: Bounded rationality and heuristic processes in exercise-related judgments and choices. Sport Exerc. Perform. Psychol. 2016, 5, 337. [CrossRef]

23. Strecher, V.; Rosenstock, I. The health belief model. In Cambridge Handbook of Psychology, Health and Medicine; Cambridge University Press: Cambridge, UK, 1997; pp. 113-117.

24. Winkielman, P.; Zajonc, R.; Norbert, S. Subliminal affective priming resists attributional interventions. Cognit. Emot. 1997, 11, 433-465. [CrossRef] 
25. Zajonc, R. Feeling and thinking: Preferences need no inferences. Am. Psychol. 1980, 35, 151. [CrossRef]

26. Edwards, M.K.; Addoh, O.; Herod, S.M.; Rhodes, R.E.; Loprinzi, P.D. A conceptual neurocognitive affect-related model for the promotion of exercise among obese adults. Curr. Obes. Rep. 2017, 6, 86-92. [CrossRef]

27. American College of Sports Medicine. ACSM's Guidelines for Exercise Testing and Prescription; Lippincott Williams \& Wilkins: Philadelphia, PA, USA, 2013.

28. Granito, V.J. History of Sport, Exercise, and Performance Psychology in North America. In Oxford Research Encyclopedia Psychology; Oxford University Press: New York, NY, USA, 2017. [CrossRef]

29. Ruby, M.B.; Dunn, E.W.; Perrino, A.; Gillis, R.; Viel, S. The invisible benefits of exercise. Health Psychol. 2011, 30, 67-74. [CrossRef]

30. Wentura, D. Dissociative affective and associative priming effects in the lexical decision task: Yes versus no responses to word targets reveal evaluative judgment tendencies. J. Exp. Psychol. Learn. Mem. Cognit. 2000, 26, 456-469. [CrossRef]

31. Klauer, K.C. Affective priming. Eur. Rev. Soc. Psychol. 1997, 8, 67-103. [CrossRef]

32. Cann, A.; Collette, C. Sense of humor, stable affect, and psychological well-being. Eur. J. Psychol. 2014, 10, 464-479. [CrossRef]

33. Loizou, G.; Karageorghis, C.I.; Bishop, D.T. Interactive effects of video, priming, and music on emotions and the needs underlying intrinsic motivation. Psychol. Sport Exerc. 2014, 15, 611-619. [CrossRef]

34. Bargh, J.A.; Gollwitzer, P.M.; Lee-Chai, A.; Barndollar, K.; Trotschel, R. The automated will: Nonconscious activation and pursuit of behavioral goals. J. Personal. Soc. Psychol. 2001, 81, 1014-1027. [CrossRef]

35. Loizou, G.; Karageorghis, C.I. Effects of psychological priming, video, and music on anaerobic exercise performance. Scand. J. Med. Sci. Sports 2015, 25, 909-920. [CrossRef] [PubMed]

36. Kay, A.; Wheeler, S.; Bargh, J.; Ross, L. Material priming: The influence of mundane physical objects on situational construal and competitive behavioral choice. Organizational Behav. Hum. Decis. Processes 2004, 95, 83-96. [CrossRef]

37. Coan, J.A.; Allen, J.J. Handbook of Emotion Elicitation and Assessment; Oxford University Press: Oxford, UK, 2007.

38. Gilman, T.L.; Shaheen, R.; Nylocks, K.M.; Halachoff, D.; Chapman, J.; Flynn, J.J.; Matt, L.M.; Coifman, K.G. A film set for the elicitation of emotion in research: A comprehensive catalog derived from four decades of investigation. Behav. Res. Methods 2017, 49, 2061-2082. [CrossRef]

39. Zacks, J.M. Flicker: Your Brain on Movies; Oxford University Press: New York, NY, USA, 2014.

40. Zacks, J.M.; Speer, N.K.; Swallow, K.M.; Braver, T.S.; Reynolds, J.R. Event perception: A mind-brain perspective. Psychol. Bull. 2007, 133, 273-293. [CrossRef]

41. Grodal, T. Moving Pictures: A New Theory of Film Genres, Feelings, and Cognition; Oxford University Press: Oxford, UK, 1999.

42. Gross, J.J.; Levenson, R.W. Emotion elicitation using films. Cognit. Emot. 1995, 9, 87-108. [CrossRef]

43. Ashford, K.; Jackson, R. Priming as a means of preventing skill failure under pressure. J. Sport Exerc. Psychol. 2010, 32, 518-536. [CrossRef]

44. Bohnen, N.; van Zutphen, W.; Twijnstra, A.; Wijnen, G.; Bongers, J.; Jolles, J. Late outcome of mild head injury: Results from a controlled postal survey. Brain Inj. 1994, 8, 701-708. [CrossRef]

45. Stulemeijer, M.; Vos, P.E.; Bleijenberg, G.; Van der Werf, S.P. Cognitive complaints after mild traumatic brain injury: Things are not always what they seem. J. Psychosomatic Res. 2007, 63, 637-645. [CrossRef]

46. Van der Naalt, J.; Van Zomeren, A.; Sluiter, W.; Minderhoud, J. One year outcome in mild to moderate head injury: The predictive value of acute injury characteristics related to complaints and return to work. J. Neurol. Neurosurg. Psychiatry. 1999, 66, 207-213. [CrossRef]

47. Stulemeijer, M.; Vos, P.E.; van der Werf, S.; Van Dijk, G.; Rijpkema, M.; Fernández, G. How mild traumatic brain injury may affect declarative memory performance in the post-acute stage. J Neurotrauma 2010, 27, 1585-1595. [CrossRef] [PubMed]

48. Faul, F.; Erdfelder, E.; Buchner, A.; Lang, A.G. Statistical power analyses using G*Power 3.1: Tests for correlation and regression analyses. Behav. Res. Methods. 2009, 41, 1149-1160. [CrossRef] [PubMed]

49. Labban, J.D.; Etnier, J.L. Effects of acute exercise on long-term memory. Res. Q. Exerc. Sport 2011, 82, 712-721. [CrossRef] [PubMed]

50. Sherman, S.M.; Buckley, T.P.; Baena, E.; Ryan, L. Caffeine enhances memory performance in young adults during their non-optimal time of day. Front. Psychol. 2016, 7, 1764. [CrossRef] [PubMed] 
51. Greenwood, J.L.; Joy, E.A.; Stanford, J.B. The physical activity vital sign: A primary care tool to guide counseling for obesity. J. Phys. Act. Health 2010, 7, 571-576. [CrossRef]

52. Ball, T.J.; Joy, E.A.; Goh, T.L.; Hannon, J.C.; Gren, L.H.; Shaw, J.M. Validity of two brief primary care physical activity questionnaires with accelerometry in clinic staff. Primary Health Care Res. Dev. 2015, 16, 100-108. [CrossRef]

53. Ekkekakis, P.; Lind, E. Exercise does not feel the same when you are overweight: The impact of self-selected and imposed intensity on affect and exertion. Int. J. Obes. 2006, 30, 652-660. [CrossRef]

54. CDC. Perceived Exertion (Borg Rating of Perceived Exertion). 2017. Available online: https://www.cdc.gov/ physicalactivity/basics/measuring/exertion.htm (accessed on 2 February 2017).

55. Borg, G. Perceived exertion as an indicator of somatic stress. Scand. J. Rehab. Med. 1970, 2, 92-98.

56. YouTube. Drunk People Falling Over (0:35-5:43). Funny Videos 2013. Available online: https://www.youtube. com/watch?v=i4MZuoNhC00. (accessed on 11 June 2019).

57. Chandrasekaran, A.; Vijayakumar, A.K.; Antol, S.; Bansal, M.; Batra, D.; Lawrence Zitnick, C.; Parikh, D. We are humor beings: Understanding and predicting visual humor. In Proceedings of the IEEE Conference on Computer Vision and Pattern Recognition 2016, Las Vegas, NV, USA, 26 June-1 July 2016; pp. 4603-4612.

58. Edwards, M.K.; Rhodes, R.E.; Loprinzi, P.D. A randomized control intervention investigating the effects of acute exercise on emotional regulation. Am. J. Health Behav. 2017, 41, 534-543. [CrossRef]

59. Bernstein, E.E.; McNally, R.J. Acute aerobic exercise helps overcome emotion regulation deficits. Cognit. Emot. 2017, 31, 834-843. [CrossRef] [PubMed]

60. Hardy, C.; Rejeski, W. Not what, but how one feels: The measurement of affect during exercise. J. Sport Exerc. Psychol. 1989, 11, 304-317. [CrossRef]

61. Svebak, S.; Murgatroyd, S. Metamotivational dominance: A multimethod validation of reversal theory constructs. J. Personal. Soc. Psychol. 1985, 48, 107. [CrossRef]

62. Frith, E.; Loprinzi, P. Experimental investigation of exercise-related, perceived hedonic responses to preferred versus imposed media content: 287 Board\# 128 May 30 9. Med. Sci. Sports Exerc. 2018, 50, 56.

63. Schaefer, A.; Nils, F.; Sanchez, X.; Philippot, P. Assessing the effectiveness of a large database of emotion-eliciting films: A new tool for emotion researchers. Cognit. Emot. 2010, 24, 1153-1172. [CrossRef]

64. Zupan, B.; Babbage, D.R. Film clips and narrative text as subjective emotion elicitation techniques. J. Soc. Psychol. 2017, 157. [CrossRef]

65. Lishner, D.A.; Cooter, A.B.; Zald, D.H. Addressing measurement limitations in affective rating scales: Development of an empirical valence scale. Cognit. Emot. 2008, 22, 180-192. [CrossRef]

66. Kang, M.; Jin, Y. Repeated ANOVA/MANOVA; John Wiley \& Sons, Inc.: New York, NY, USA, 2016.

67. Loprinzi, P.D. Objectively-measured physical activity and predicted 10-yr risk for a first atherosclerotic cardiovascular disease (ASCVD) event using the pooled cohort risk equations among US adults. Int. J. Cardiol. 2015, 199, 31-32. [CrossRef] [PubMed]

68. Loprinzi, P.D.; Ramulu, P.Y. Objectively measured physical activity and inflammatory markers among US adults with diabetes: Implications for attenuating disease progression. Mayo Clin. Proc. 2013, 88, 942-951. [CrossRef] [PubMed]

69. Pratt, M.; Norris, J.; Lobelo, F.; Roux, L.; Wang, G. The cost of physical inactivity: Moving into the 21st century. Br. J. Sports Med. 2014, 48, 171-173. [CrossRef]

70. Hagberg, L.A.; Lindahl, B.; Nyberg, L.; Hellenius, M.L. Importance of enjoyment when promoting physical exercise. Scand. J. Med. Sci. Sports 2009, 19, 740-747. [CrossRef]

71. Edwards, M.K.; Loprinzi, P.D. Effects of a sedentary behavior-inducing randomized controlled intervention on depression and mood profile in active young adults. Mayo Clin. Proc. 2016, 91, 984-998. [CrossRef] [PubMed]

72. Jaffery, A.; Edwards, M.K.; Loprinzi, P.D. Randomized control intervention evaluating the effects of acute exercise on depression and mood profile: Solomon experimental design. Mayo Clin. Proc. 2017, 92, 480-481. [CrossRef]

73. Ekkekakis, P.; Hall, E.E.; Petruzzello, S.J. Some like it vigorous: Measuring individual differences in the preference for and tolerance of exercise intensity. J. Sport Exerc. Psychol. 2005, 27, 350-374. [CrossRef]

74. Gee, D.L.; Moore, K.A. Dispositional, situational and motivational factors in exercise adoption and adherence. In Advances in Health Psychology Research; Schwarzer, R., Ed.; Freie Universität Berlin: Berlin, Germany; ISBN 3-00-002776-9. 
75. Simonavice, E.M.; Wiggins, M.S. Exercise barriers, self-efficacy, and stages of change. Percept. Mot. Skills 2008, 107, 946-950. [CrossRef]

76. Williams, D.M. Exercise, affect, and adherence: An integrated model and a case for self-paced exercise. J. Sport Exerc. Psychol. 2008, 30, 471-496. [CrossRef] [PubMed]

(C) 2020 by the authors. Licensee MDPI, Basel, Switzerland. This article is an open access article distributed under the terms and conditions of the Creative Commons Attribution (CC BY) license (http://creativecommons.org/licenses/by/4.0/). 